\title{
Potential Assessment of Modelling Performance of a Central Tower Receiver Power Plant Using Intelligent Control Technique
}

\author{
Ibrahim Moukhtar ${ }^{1,2, *}$, Adel A. Elbaset ${ }^{3}$, Adel Z. El Dein $^{2}$ and Yasunori Mitani ${ }^{1}$ \\ ${ }^{1}$ Electrical and Electronics Engineering Department, Kyushu Institute of Technology, Kitakyushu, Japan. \\ ${ }^{2}$ Electrical Engineering Department, Faculty of Energy Engineering, Aswan University, Aswan, Egypt. \\ ${ }^{3}$ Electrical Engineering Department, Faculty of Engineering, Minia University, Minia, Egypt.
}

Received 28 March 2018; Accepted 18 August 2018

\begin{abstract}
Recently, central tower receiver (CTR) power plant has been received a considerable attention as a promising technology for large solar thermal plants compared to different concentrated solar power (CSP) technologies. The present work adopted a facile controllable scheme using an artificial neural network (ANN) technique for modelling and simulating CTR plant with thermal energy storage (TES). Three different ANN models such as radial basis function (RBF), generalized regression neural network (GRNN), and multi-layer perceptron (MLP) were applied to assess the performance of CTR plant model. Based on statistical error analysis, MLP model was the optimal model compared to RBF and GRNN models. It is found that MLP model displays the best values for the coefficient of determination (R2=1), root mean square error (RMSE $=0.003$ ) and mean absolute error (MAE $=0.0023$ ) during ANN testing process. While, the values of R2, RMSE, and MAE were $0.999,0.4817$, and 0.32 , respectively for GRNN model. Similarly, for RBF model, the values of R2, RMSE, and MAE were 0.9985, 0.2846, and 0.0674, respectively. The MLP provides a precise control over the discharge rate of the heat transfer fluid (HTF). Therefore, the receiver outlet temperature remains constant at the desired value regardless of the variations in direct solar radiation and receiver inlet temperature. Also, in this work, the algorithm of electrical generation methodology was modified for regulating CTR/TES output according to the hot storage tank (HST) conditions. The adopted model performance for a $40 \mathrm{MWe}$ CTR power plant is validated by comparing its results with the obtained simulation results by System Advisor Model (SAM) software. The simulation results exhibit that the adopted CTR-ANN model and SAM results are in good agreement with each other. The reasonable simplicity and minimum required input data of CTR-ANN model make it an adequate tool to predict and analyse the performance of CTR technology in a simple and fixable manner.
\end{abstract}

Keywords: Concentrated solar power, central tower receiver, power regulation, artificial neural network, mass flow rate.

\section{Introduction}

In the past few decades, solar energy systems (SES) have been received great attention as an important source of renewable energy. The advantages of solar energy (e.g., clean, abundant, a source with a free cost, and environmentally friendly energy solutions) make it one of the most promising technology in the world. Generally, renewable energy sources (RES) technologies are considered as a substitutional solution to reduce $\mathrm{CO}_{2}$ emission [1,2]. As well as, the environmental and finical problems of conventional plants led to an increase of the dependence of electric grid on SES. Nowadays, SES types (i.e., CSP and PV) constitute appropriate commercial options for small and large power plants [2]. The CSP/TES plays a vital role in power generation, especially during cloudy weather periods and after sunset. More significantly, the International Energy Agency (IEA) reported that the expected contribution of CSP technology will supply over $10-11.3 \%$ of electricity production in the world by 2050 [3-5].

The CSP/TES exhibited advantageous characteristics over other energy resources such as [6,7]: (a) The inherent

*E-mail address: Ibrahim_mokhtar@aswu.edu.eg

ISSN: $1791-2377 @ 2018$ Eastern Macedonia and Thrace Institute of Technology. All rights reserved. doi:10.25103/jestr.116.13 flexibility that provides the overall grid flexibility. (b) Close resemblance to traditional power plants (i.e., uses many of the same equipment and technologies). (c) At large scale of CSP plants, TES does not consider the major part of generation cost. This considers the prime merit of CSP/TES system compared to other technologies that use the electrical storage forms. Based on the method type of collecting and concentrating solar radiation, CSP technologies can be divided into four main categories [8-9]. These four main technologies are; central tower receiver (CTR), parabolic trough (PT), parabolic dish (PD) and linear Fresnel reflector (LFR). Recently, the CTR plant has drawn extensive attention as a suitable candidate for large solar thermal plants. Also, this technology displayed higher energy efficiencies than other CSP technologies because of its high operating temperature. For this reason, the thermal energy storage cost has reduced [10].

As mentioned above, the growing of integrated CSP systems in electric power network creates the need for comprising them in electrical grid reliability studies. There are two techniques for evaluating power system reliability [11]: (1) Analytical techniques; more efficient if the operating conditions are not complex. (2) Monte Carlo (MC) simulation approach; often preferable when the operating conditions are complex and the number of events is comparatively large. Furthermore, there are several accurate 
models and software programs have been used to model and analyse the performance of CSP technologies as presented in [12-16]. However, they do not offer the desired simplicity. For example, one of the famous programs is the System Advisor Model (SAM) software, which was developed by NREL to simulate the output power of RES [17-118]. SAM software needs more than 90 input parameters to describe an individual CSP technology [19]. Therefore, SAM and other software may not be appropriate to assess the power system reliability by using MC method because of the increased uncertainty in simulation results. The increased uncertainty may arise from the following reasons: complex operating condition, several required input data, need more experience and knowledge, and long computational time [19].

The solar power plants differ than conventional power plants due to the variable nature of the main energy source (i.e., direct solar radiation), which can't be manipulated. In addition, the direct beam radiation relies on the weather conditions such as humidity, clouds, and air transparency. Therefore, an effective control method is necessary to achieve the required operating conditions despite any variations in the input parameters of this plant kind. Different control methods were applied for controlling the outlet temperature of CSP technologies power plants. The control problem aspects, to fulfil an appropriate performance along the operating range, are summarised in [20,21]. However, the objective of the proposed control technique should be able to continuously regulate HTF outlet temperature. This can be done by adjusting the HTF mass flow rate over the operation cycle.

Artificial neural network (ANN) is one of the most used soft computing tools in many different applications, especially, in the field of solar energy systems [22-24]. Compared to other traditional methods, ANN technique is an accurate tool to solve the complex and nonlinear problems and consume less time. In view of this, in the present study, three different models of ANN approach; RBF, GRNN, and MATLAB Simulink model of CTR plant MLP, were used for modelling and predicting the output power of the CTR plant. A total of 888 datasets were obtained by calculating the HTF discharge rate at different points of the receiver inlet temperature. The proposed model was applied to control the HTF mass flow rate from a cold storage tank (CST) and that passes through a tower receiver. Hence, the receiver outlet temperature is still constant at the desired value. The results show that MLP model with 40 neurons represented the optimal topology. The optimized model is selected based on the criteria of best performance (statistical evaluation). The accuracy of ANN model was satisfactory, so the integrated CTR-ANN model can overcome the obstacles of classical computational models and software programs. Further, the electrical generation strategy algorithm was modified to regulate CTR/TES output according to HST conditions as explained in section (6). The obtained results of the CTRANN model are compared to those obtained from SAM software to confirm its validity. The proposed model results confirm that the model can be suitable for predicting the electrical output power of CTR plant.

\section{Description of CTR power plant}

The capacity of proposed CTR plant model is $40 \mathrm{MWe}$ under Aswan climate, Egypt (latitude: $23.97{ }^{\circ} \mathrm{N}$ and longitude: $32.78^{\circ} \mathrm{E}$ ). The main three parts of CTR plant components are exhibited in Fig. 1(a) such as solar energy collection and concentration (i.e., heliostats field and tower receiver system), HTF and storage system (i.e., CST, HST and molten salt), and power block (PB) system (i.e., steam generator, turbine and electric generator) [25]. In this research, the mathematical model of this plant is implemented in MATLAB/Simulink as described in Fig. 1(b). The main parameters for CTR modelling are described in Table 1 .

As shown in Fig. 1(a), the operation process of the CTR/TES plant is as follows: during daylight periods, the heliostats field collect sun rays and reflect them toward the tower receiver. In this moment, the HTF (molten salt) is pumped at $290^{\circ} \mathrm{C}$ from CST into the tower receiver to heat it up to $565^{\circ} \mathrm{C}$. Then the hot HTF is stored in HST. When the electrical energy is required, the stored hot molten salt is pumped through a heat exchanger to produce the required superheated steam. After that, the classical power block (Rankine cycle turbine/generator system) is operated to generate the electricity.

Table 1 Input parameters of CTR model

\begin{tabular}{lc}
\hline Parameters & Value \\
\hline$L$ & $23.97^{\circ} \mathrm{N}$ \\
$L_{l o c}$ & $32.78^{\circ} \mathrm{E}$ \\
$L_{s t}$ & $30^{\circ}$ \\
$\rho$ & 0.2 \\
$P_{\text {gross }}$ & $40 \mathrm{MW}$ \\
$T_{H T F, \text { hot }}$ & $565^{\circ} \mathrm{C}$ \\
$T_{H T F, \text { cold }}$ & $290{ }^{\circ} \mathrm{C}$ \\
$\eta_{t h}$ & $40 \%$ \\
$\eta_{\text {gen }}$ & $95 \%$ \\
$D N I$ & $950 \mathrm{~W} / \mathrm{m} 2$ \\
$A_{h s}$ & $12.2 \mathrm{mx} 12.2 \mathrm{~m}$ \\
$\eta_{r e f}$ & $88 \%$ \\
$N_{h s}$ & 1480 \\
\hline
\end{tabular}

\section{CTR mathematical modelling}

\subsection{Solar position and radiation}

The first step of modelling CTR power plant is the calculation of the sun position considering heliostat and receiver position. In this research, the sun position is calculated for the location of Aswan city in Egypt. Solar altitude angle $\left(\alpha_{s}\right)$ and azimuth angle $\left(\gamma_{s}\right)$ are two important angles for finding the sun position, which can be calculated as follows $[26,27]$ :

$$
\begin{aligned}
& \alpha_{s}=\sin ^{-1}\left(\sin \delta_{s} \cdot \sin L+\cos \delta_{s} \cdot \cos L \cdot \cos h_{s}\right) \\
& \gamma_{s}=\sin \left(h_{s}\right)\left|\cos ^{-1}\left(\frac{\cos \theta_{z} \sin L-\sin \delta_{s}}{\sin \theta_{z} \cos L}\right)\right|
\end{aligned}
$$

Calculation details of $\delta_{s}, h_{s}$, and $\theta_{z}$ are given in appendixA. The incidence beam angle $(\theta)$ is an important aspect for the solar energy system design; where the amount of solar thermal energy that could reach the tower receiver depending on this angle. The maximum amount of solar energy at the receiver is decreased by the cosine of this angle $[28,29]$. The incidence angle, in general form for fixed and tracking surfaces, is calculated as follows [30]:

$$
\theta=\cos ^{-1}\left(\cos \theta_{z} \cos \beta+\sin \theta_{z} \sin \beta \cos \left(\gamma_{s}-\gamma\right)\right)
$$




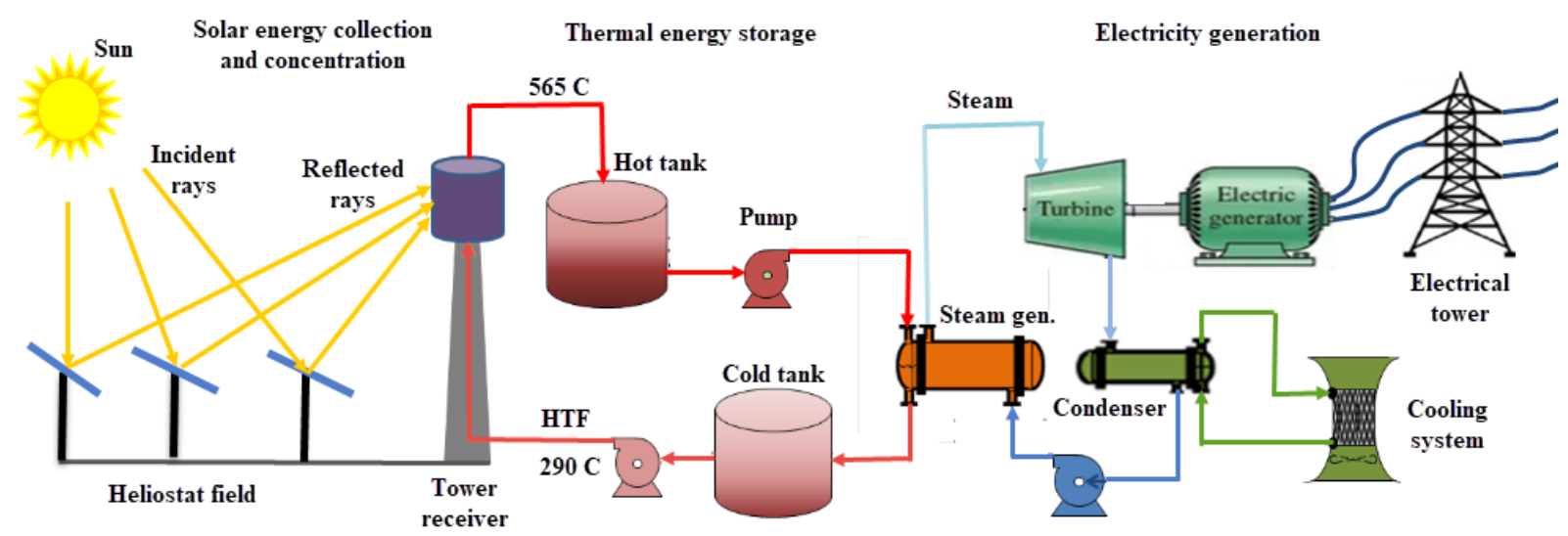

(a)

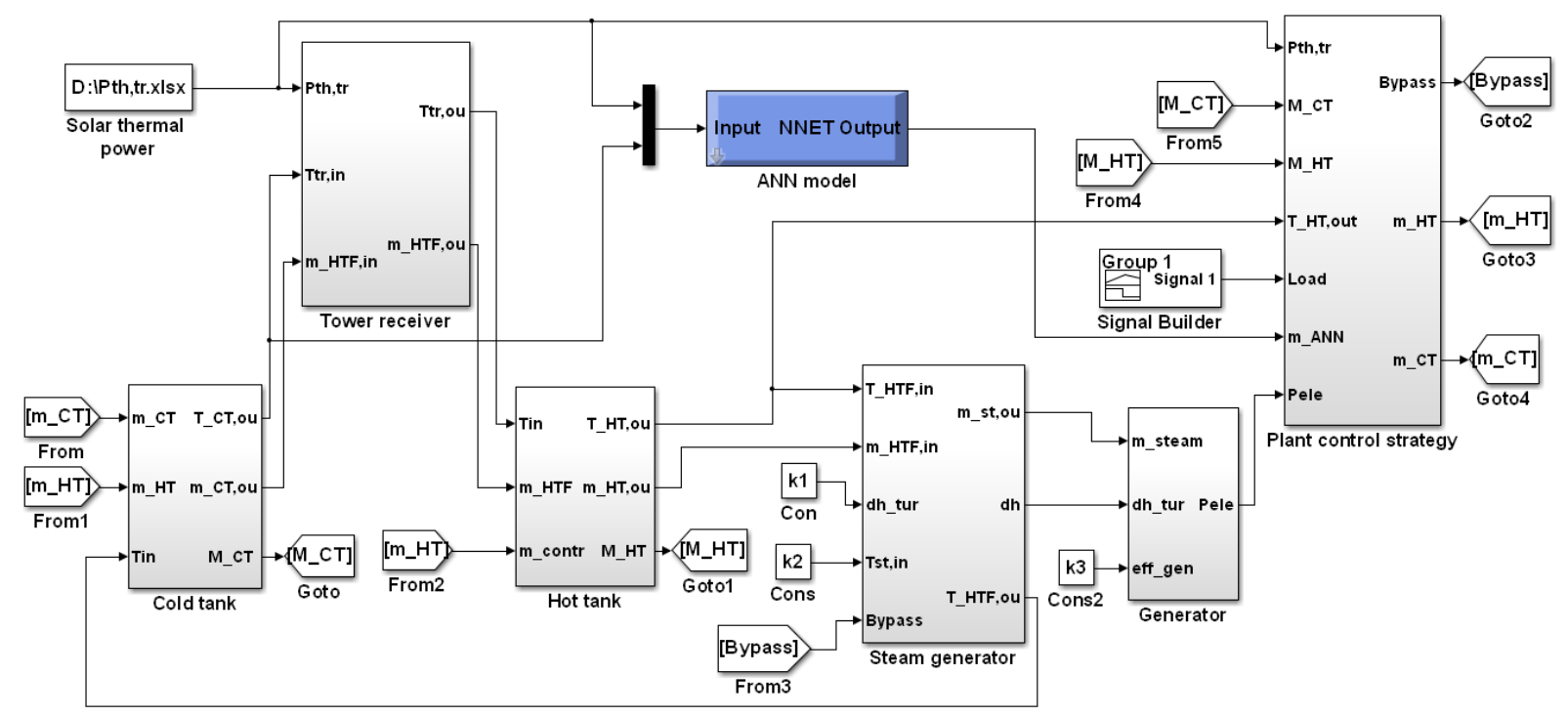

(b)

Fig. 1. (a) Schematic diagram of CTR plant components and (b)

The incidence angle for a plane rotated about a horizontal east-west axis with a single daily adjustment is determined as follows [29]:

$\theta=\cos ^{-1}\left(\sin ^{2} \delta_{s}+\cos ^{2} \delta \cosh \right)$

In this case, the surface slope $(\beta)$ and surface azimuth $(\gamma)$ are given by [29]:

$\beta=\left|\emptyset-\delta_{s}\right|$

$\gamma= \begin{cases}0 & \text { if } L-\delta_{s}>0 \\ 180 & \text { if } L-\delta_{s} \leq 0\end{cases}$

There are several attenuations in solar radiation to reach the earth's surface. Only the direct and diffuse solar radiations reach the earth's surface. There are many mathematical approaches for estimating the solar radiation. Daily Integration (DI) approach is one of the accurate methods that is used to calculate the hourly solar radiation. The total radiation, I, on a tilted surface is obtained from Eq. (7) [26].

$I=\left(r_{t} \bar{H}_{h}-r_{d} \bar{H}_{d}\right) \frac{\cos \theta}{\sin \alpha_{s}}+r_{d} \bar{H}_{d} \cos ^{2} \frac{\beta}{2}+\rho r_{t} \bar{H}_{h} \sin ^{2} \frac{\beta}{2}$ where $r_{t}$ and $r_{d}$ parameters are given in appendix A, while $\hat{H}_{h}$ and $\hat{H}_{d}$ are obtained from NASA's Applied Science Program [30].

\subsection{Receiver solar thermal power}

The solar thermal power $\left(P_{t h, t r}\right)$ reflected by the entire heliostat field into the tower receiver equals to the sum of the field efficiency of each heliostat $\left(\eta_{f i l d}\right)$, heliostat area $\left(A_{h s}\right)$ and the reflected solar radiation by each heliostat [19].

$P_{t h, t r}=\sum I A_{h s} \eta_{\text {field }}$

The field efficiency $\eta_{\text {field }}$ is obtained from Eq. (9) [31].

$\eta_{\text {field }}=\sum \eta_{\text {cos }} \eta_{\text {att }} \eta_{\text {sb }} \eta_{\text {ref }}$

\subsection{Power block and steam generator model}

The used power cycle in the plant $\mathrm{PB}$ is a conventional Rankine steam cycle. The hot molten salt (HTF) passes through a heat exchanger to produce a superheated steam. Shell and tube heat exchanger is the common type of the heat exchanger that is used in the solar power plants [32]. The heat exchanger is modelled for partial load conditions in order to accommodate the load demand nature and intermittent solar energy, especially during the periods of cloudy weather and after sunset. Therefore, the outlet steam flow rate depends on the required power from the heat 
exchanger; thus, the HTF inlet mass flow rate is variable to maintain constant steam temperature through the operation cycle. The effectiveness-NTU method is the better method to calculate the actual heat transfer rate [33].

$$
\varepsilon=\frac{Q}{Q_{\max }}
$$

For a shell and tube heat exchanger and in the case of partial load conditions, the actual heat transfer rate and the heat transfer unit (NTU) are simplified as in Eqs. (11) and (12) [34-36], respectively.

$$
\begin{aligned}
& Q=\varepsilon Q_{\max } \\
& \quad=\left(1-e^{-N T U}\right) \dot{m}_{H T} C_{H T F}\left(T_{H T F, \text { in }}-T_{\text {steam }, \text { in }}\right) \\
& N T U=\left(\frac{\dot{m}_{H T, \text { ref }}}{\dot{m}_{H T}}\right)^{0.2} N T U_{\text {ref }}
\end{aligned}
$$

where $C_{H T F}$ is HTF specific heat, $\dot{m}_{H T}$ is outlet mass flow rate from HST that equals to inlet mass flow rate to the heat exchanger, $T_{H T F, \text { in }}$ is HTF inlet temperature to the heat exchanger, and $T_{\text {steam,in }}$ is steam inlet temperature to the heat exchanger, $N T U_{\text {ref }}$ and $\dot{m}_{H T \text {,ref }}$ are the heat transfer unit and HTF mass flow rate at the reference full-load condition, respectively. Furthermore, the steam flow rate and the electrical output power of CTR are introduced in Eqs. (13) and (14) [37]:

$$
\begin{aligned}
& \dot{m}_{\text {steam }}=\frac{\dot{Q}}{\Delta h_{t u r}}=\frac{\left(1-e^{-N T U}\right) \dot{m}_{H T}\left(T_{H T F, \text { in }}-T_{\text {steam }, i n}\right)}{\Delta h_{t u r}} \\
& P_{\text {ele }}=W_{t} \cdot \eta_{\text {gen }}=m_{\text {steam }} \Delta h_{\text {tur }} \eta_{\text {gen }}
\end{aligned}
$$

where $\dot{m}_{\text {steam }}$ is the steam mass flow rate $(\mathrm{kg} / \mathrm{s}), \Delta h_{\text {tur }}$ is the difference between the inlet and outlet enthalpy of the turbine steam $(\mathrm{J} / \mathrm{kg}), W_{t}$ is the total turbine work, $\eta_{g e n}$ is the generator efficiency and Pele is the electrical output power of CTR.

\section{Artificial neural network}

ANN is an efficient computing algorithm that emulates the biological neurons performance for the basic functions such as the human brain. These functions have an ability to determine the nonlinear relationship between the inputs and the outputs, where they perform the following processes [38]: receive the inputs from neurons or other sources, combine them and execute operations on the result to give the final output result. More details about ANN and how training it, to be ready for the application, were presented in these references [38-40]. After training, ANN model becomes ready to perform its function in a self-organized method such as the human brain in its functions. Fig. 2 describes the basic structure ANN technique and its training process via a comparison between output and target. Several types or models of ANN are categorised by their structures and abilities. In this work, radial basis function (RBF), generalized regression neural network (GRNN), and multilayer perceptron (MLP) were used.

\subsection{RBF neural network}

$\mathrm{RBF}$ is a functional approximation network which can be applied in control, memorization and identification. It is able to effectively learn system behaviours, therefore, it used for nonlinear systems identification [41]. As demonstrated in
Fig. 3, RBF consists of three layers: input layer, hidden layer, and output layer. In this model, the signal is collected at the input layer and it is passed through the hidden layer. These signals are processed in the hidden layer until they are ready to be sent to the output layer, which generates the output data [42]. The RBF for $j^{\text {th }}$ node in the hidden layer is given by Gaussian exponential function as follows [23]:

$b_{j}(x)=\exp \left[\frac{-\left\|X_{i}-\mu_{j}\right\|^{2}}{2 \sigma_{j}^{2}}\right]$

where $\sigma_{j}$ is the width of $j^{\text {th }}$ neuron (spread factor), and $X_{i}$ and $\mu_{j}$ are the input and centre of RBF unit, respectively.

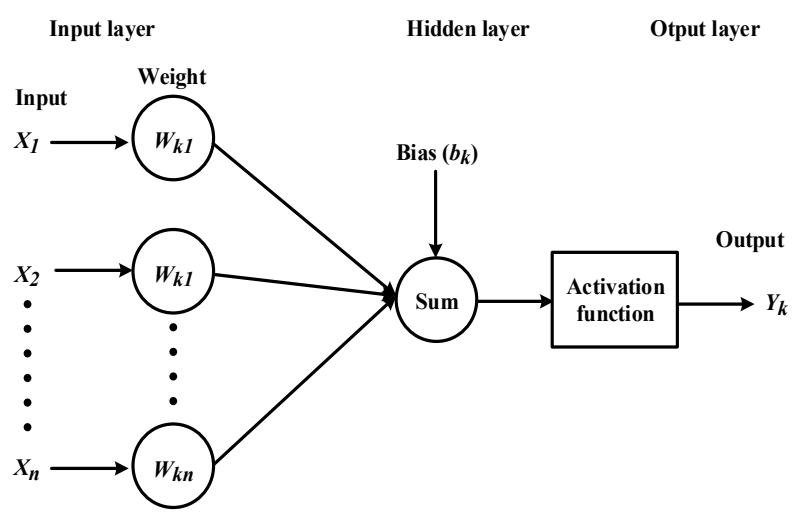

(a)

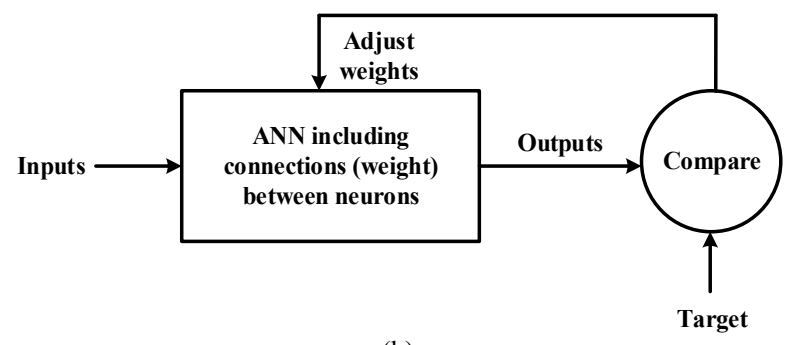

(b)

Fig. 2. Artificial neural network: (a) Basic structure and (b) Schematic diagram of the basic training process

The network output $Y_{k}$ for the output layer is linear, which is given by Eq. (16) [23].

$Y_{k}(x)=\sum_{j=1}^{n} W_{k j} b_{j}(x)+b_{k}$

where $b_{k}$ and $W_{k j}$ are is the bias and weight connection between the hidden layer nodes and output layer node, respectively.

\subsection{MLP neural network}

As regard in Fig. 4, MLP model is similar to RBF construction, which consists of three layers: input layer, one or more hidden layers, and an output layer. MLP is a useful neural network in function approximation like RBF neural network and both of them are feed-forward neural network [41]. MLP with a single hidden layer can approximate any complex function. Each layer includes a certain number of neurons or nodes, which can determine the nonlinear relationship between the inputs and the outputs [43]. These neurons perform the following processes: receiving the inputs from neurons or other sources, combining them, and executing nonlinear operations on the result to give the final 
output result. Each neuron output is a result of the inputs weighted set. The weighted inputs created by neurons are determined as follows [41]:

$$
S=\left(\sum_{i=1}^{n} W_{i j} X_{i}\right)+b_{j}
$$

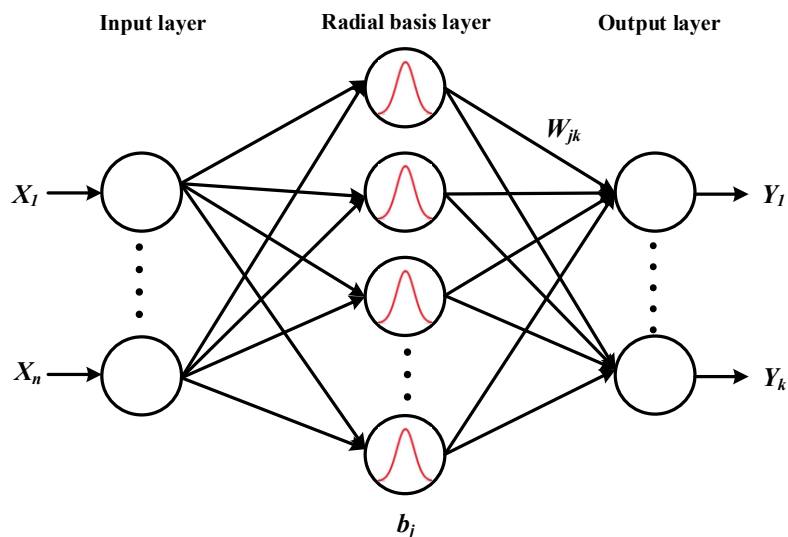

Fig. 3. Basic construction of RBF model

Then, the sum of $S$ passes through a transfer function $(F)$, which produces an output as the following [41]:

$Y=F(S)=F\left[\left(\sum_{i=1}^{n} W_{i j} X_{i}\right)+b_{j}\right]$

where $X_{i}, w_{i j}$, and $b_{j}$ are inputs data, weights, and bias of neurons, respectively.

The network architecture (i.e., the hidden layer number and neuron number) influences on the network training and therefore the predicting performance. On the other hand, there is no systematic rule for giving the optimal neuron number in the hidden layer to get the best network performance. Indeed, most of the researchers have adopted the methodology of trial and error for selecting the neuron numbers in the hidden layers [43].

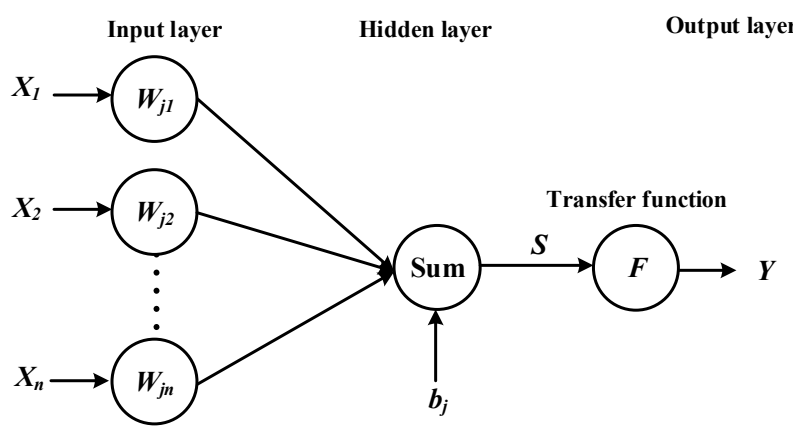

Fig. 4. Basic construction of MLP model

\subsection{GRNN neural network}

GRNN is also often utilized as function approximation and it is based on a probabilistic model. GRNN includes a radial basis layer and a special linear layer. Subsequently, it is similar to RBF network in its construction but has a slightly different second layer [41]. The GRNN model structure comprises four layers as follows: input layer, pattern layer, summation layer and an output layer as shown in Fig. 5.

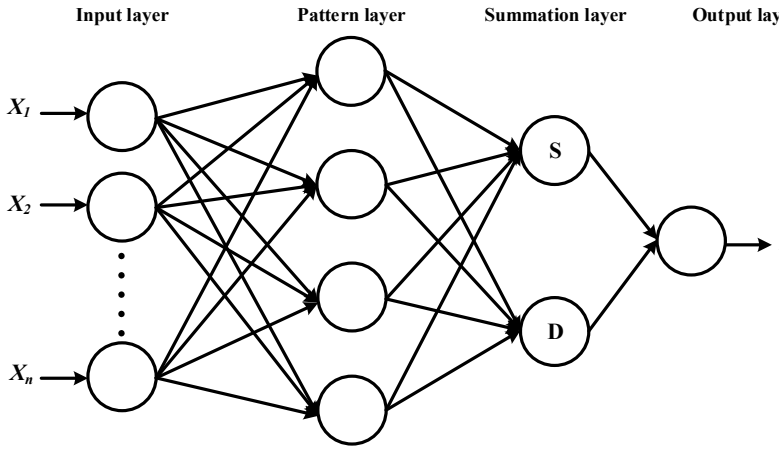

Fig. 5. Basic construction of GRNN model

The information is collected by the input layer and transmitted to the pattern layer that performs clustering on the training process. Then it passes through the summation layer, which includes only two neurons: (a) S- Summation neuron and (b) D-Summation neuron [44].

$$
\begin{aligned}
& S=\sum_{i=1}^{n} W_{i} \exp \left[-D\left(X, X_{i}\right)\right] \\
& D=\sum_{i=1}^{n} \exp \left[-D\left(X, X_{i}\right)\right]
\end{aligned}
$$

The fourth layer (output layer) executes the output normalization as given in Eq. (21) [44].

$Y(X)=\frac{\sum_{i=1}^{n} W_{i} \exp \left[-D\left(X, X_{i}\right)\right]}{\sum_{i=1}^{n} \exp \left[-D\left(X, X_{i}\right)\right]}$

where $\mathrm{D}(\mathrm{x}, \mathrm{xi})$ is the Gaussian function and is defined as [44]:

$D\left(X, X_{i}\right)=\sum_{j=1}^{P}\left(\frac{x_{j}-x_{i j}}{\sigma_{j}}\right)^{2}$

where $p$ is the elements number of an input vector. The terms $x_{j}$ and $x_{i j}$ represent the $j^{\text {th }}$ element of $X$ and $X_{i}$, respectively.

\subsection{Criteria of optimal ANN model}

The performance of ANN models is evaluated by many different statistical parameters such as the coefficient of determination $\left(R^{2}\right)$, root mean square error (RMSE), and mean absolute error (MAE). The optimal ANN model is that achieves the lowest error (preferred to be 0 or close to 0 ) and gives the highest value of R2 (expected to reach 1 or close to $1)$, which are given as [43]:

$$
\begin{aligned}
& R M S E=\sqrt{\frac{1}{2} \sum_{i=1}^{n}\left(X_{\text {actual }, i}-X_{\text {predicted }, i}\right)^{2}} \\
& M A E=\frac{1}{n} \sum_{i=1}^{n}\left|X_{\text {actual }, i}-X_{\text {predicted }, i}\right| \\
& R^{2}=1-\frac{\sum_{i=1}^{n}\left(X_{\text {actual }, i}-X_{\text {predicted }, i}\right)^{2}}{\sum_{i=1}^{n} X_{\text {predicted }, i}^{2}} \\
& A R E=\frac{\left|X_{\text {actual }, i}-X_{\text {predicted }, i}\right|}{X_{\text {actual }, i}}
\end{aligned}
$$

where $X_{\text {actual }}, X_{\text {predicted, }}$ and $n$ are the actual value (target), predicted value by the ANN model, and the total number of samples, respectively. 


\section{Mass flows rate estimation based on ANN}

In this work, three ANN models such as MLP, RBF, and GRNN were used for estimating the HTF discharge rate from the cold tank. The discharge rate amount depends on two parameters as exemplified in Fig. 6. The first parameter is $X_{l}$; the solar thermal power $\left(P_{t h, t r}\right)$ at the tower receiver. The second is $X_{2}$; the receiver inlet temperature $\left(T_{i n, t r}\right)$ of the HTF mass flow rate. $X_{1}$ and $X_{2}$ are the inputs of ANN model and its output is $Y$ (HTF discharge rate amount).

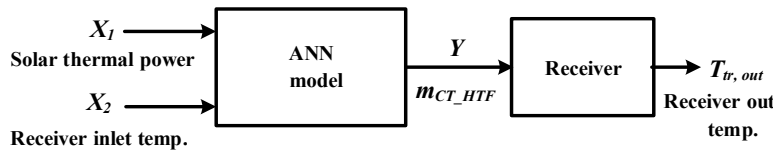

Fig. 6. Block diagram of mass flow rate and temperature control using ANN

The HTF mass flow rate from the cold storage $\left(\dot{m}_{C T}\right)$ has been calculated by applying the energy balance equation at the tower receiver [34].

$\dot{m}_{C T}=\frac{\eta_{r e c} P_{t h, t r}}{C_{H T F}\left(T_{t r, i n}-T_{t r, o u t}\right)}$

where $T_{t r, \text { in }}$ and $T_{t r, \text { out }}$ are the inlet and outlet receiver temperature, respectively, and $\eta_{\text {rec }}$ is the receiver thermal efficiency.

The models of ANN approach were trained based on Eq.(27) in order to estimate the HTF discharge rate. The performance of ANN models were evaluated with a goal equals to $10^{-5}$. While the training results present the best performance $\left(\mathrm{MSE}=7.2 \mathrm{e}^{-5}\right)$ and highest value of correlation coefficient $(R=1)$ as seen in (Fig. 7). This demonstrates that the ANN technique performs well and continuously adjusts HTF mass flow rate according to the inputs values as displayed in the testing result (Fig. 8). The receiver outlet temperature relies on the amount of mass flow rate, receiver inlet temperature, and solar intensity concentrated on the receiver. Consequently, the ANN technique precisely controls the receiver outlet temperature to remain constant at the desired value. As a result of the accuracy of ANN model that was satisfactory as explained above, it can be used in the modelling of CTR plant with a minimum required input data and knowledge.

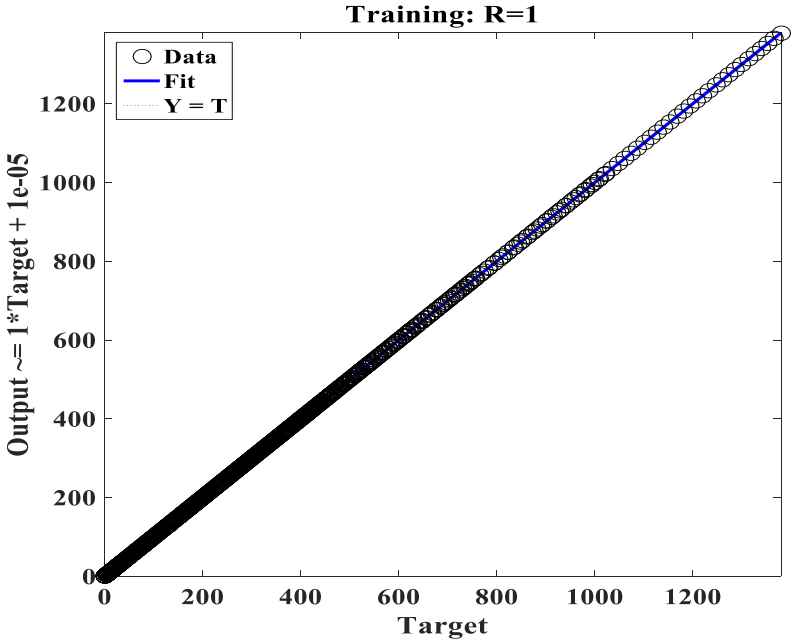

(a)

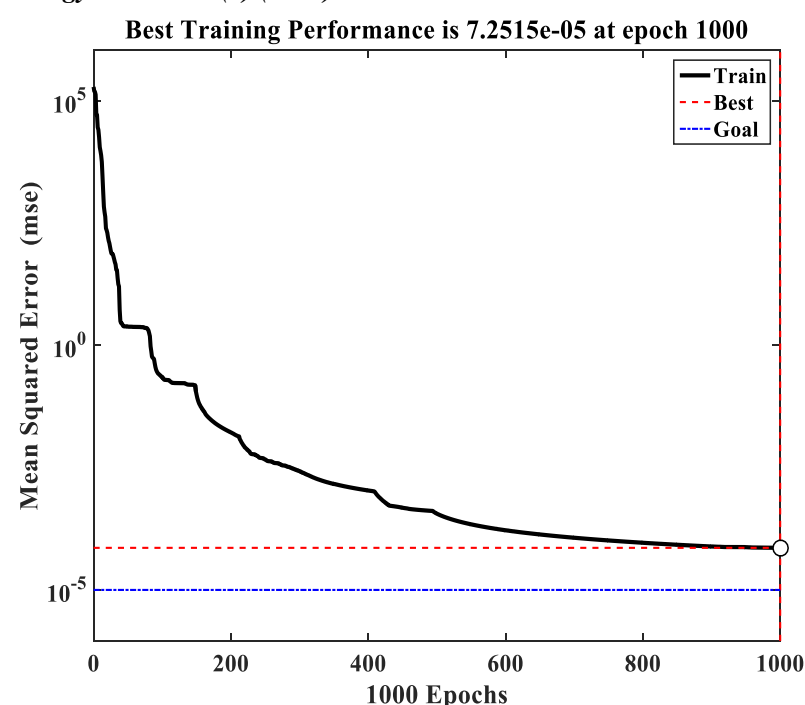

(b)

Fig. 7. Training results of ANN model: (a) Model regression and (b) Model performance

\section{The algorithm strategy of electricity generation}

The operation strategy of CTR plant is an important aspect, which ensures the correct operation of each component of this plant under specified conditions. Fig. 9 describes a simplified diagram of the plant operation algorithm. The calculation details of this algorithm are given in section (3). In this model, a current implemented strategy for deciding plant operation modes depends on solar thermal power, conditions of storage systems, and HST outlet temperature. Most of studies and research in this field carried out a control logic of CTR plant based on the following strategy: firstly, PB is directly fed from SF. Secondly, HST begins discharging for feeding $\mathrm{PB}$ when the available SF power is less than the required power $[45,46]$. However, in this work, $\mathrm{SF}$ power is directly stored in a HST. Then, PB is fed from the HST depending on its conditions (i.e., its temperature and amount of HTF mass within it). This strategy is used to regulate the generated power, which may be useful when a CTR plant is used to feed a certain demand (e.g., supplying loads in desert regions). However, for output power control, there are several advanced optimization and control schemes can be applied to maximize the total benefit and minimize the operating costs [16].
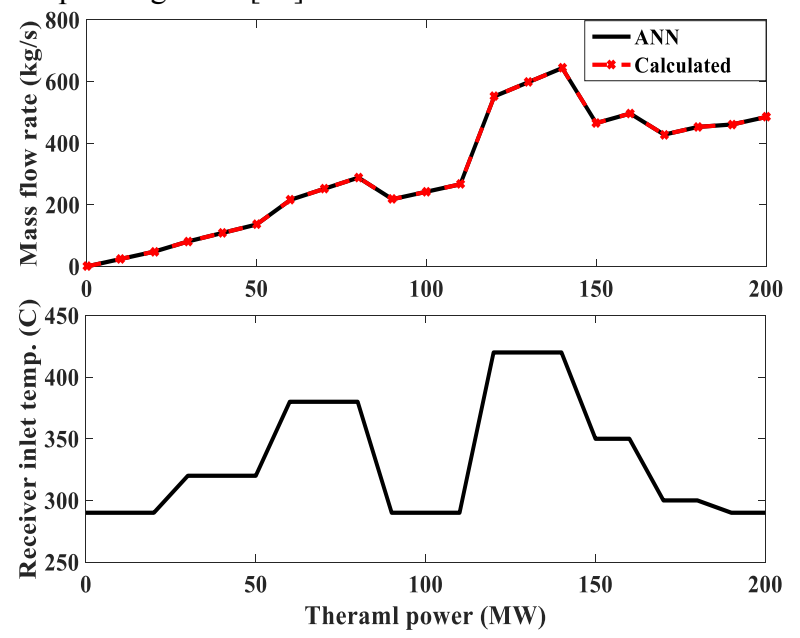

Fig. 8. Comparison between calculated mass flow rate and estimated by ANN 
The general aspects of operation modes strategy are summarized in Fig. 9 as follows:

- Initially, assumed that the state of CST and HST are full and empty, respectively.

- When the solar thermal energy is more than the minimum value $\left(P_{\min }\right)$ as in Eq. $(28)$, the algorithm begins to discharge molten salt from CST that is heated through the receiver and stored in HST.

- Similarly, HST starts to discharge when the mass within HST reaches a predetermined value $\left(M_{\text {run }}\right)$. While the discharge is stopped when the mass reaches a minimum value $\left(M_{s t}\right)$, which make the pump able to extract any molten salt from the tank.

- Bypass state depends on HST outlet temperature $\left(T_{H T, o u t}\right)$. Therefore, the bypass valve opens when $T_{H T \text {,out }}$ falls below the temperature setting $\left(T_{s t}\right)$. In this case, the molten salt directly passes from HST to CST and PB does not produce electricity.

- The minimum value of solar thermal energy $\left(P_{\min }\right)$ is given by the following equation [19]:

$P_{\text {min }}=I_{\text {min }} A_{\text {hs }} \eta_{\text {field }}$

\section{Simulation results and discussion}

In the present work, RBF, MLP, and GRNN are three different types of ANN models, which were applied for estimating HTF mass flow rate. For training purpose, the three models were examined with an increased number of spread factor and neurons to determine the output accurately. As well as, the Levenberg-Marquardt (LM) training algorithm was selected for training MLP model. Additionally, several inputs and outputs of the model parameters have been simulated such as the hourly solar radiation, receiver solar thermal power, mass flow rate, receiver outlet temperature, and electrical output power. The performance of the adopted CTR-ANN model was analysed and implemented using MATLAB/Simulink as described in Fig. 1(b). The obtained results by SAM software were exported to MATLAB ${ }^{\circledR}$ to perform a comparison between the results of SAM and the adopted CTR-ANN model. All the simulation results have been carried out with solar multiple (SM) equals one. SM is the ratio between the actual SF size and its size required to supply the turbine at its nameplate capacity with maximum solar radiation.

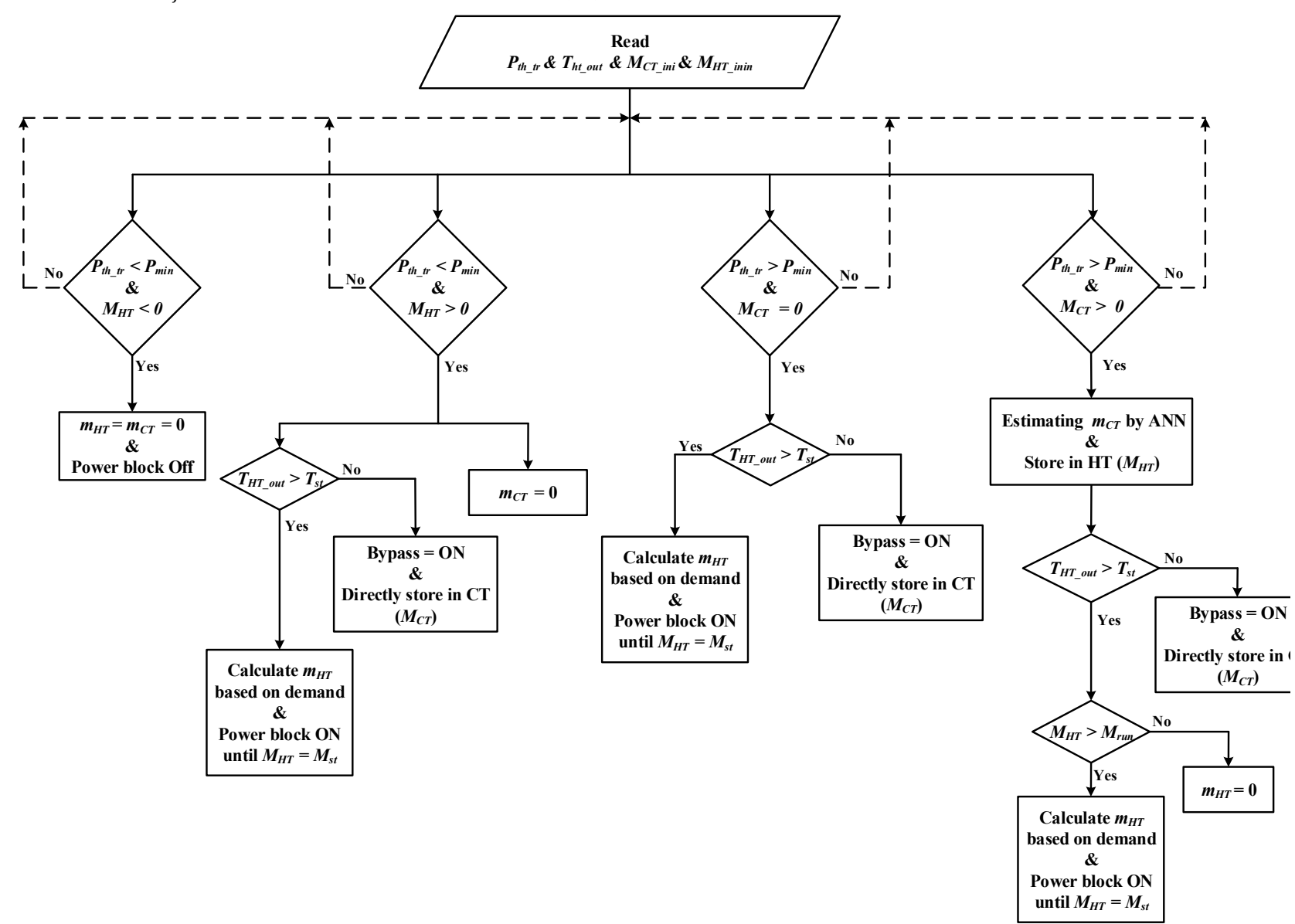

Fig. 9. Schematic diagram of the operating modes decisions for CTR/TES plant

The performance of ANN models is studied based on the statistical analysis such as RMSE, MAE and $R^{2}$. The optimal model is that achieves the lowest error values (should be 0 or close to 0 ) and the highest value of $\mathrm{R} 2$ (preferred to be1 or close to 1). The testing results of the performance evaluation for GRNN, RBF, and MLP models are summarized in Tables 2, 3 and 4, respectively. Additionally, the comparison of the calculated and estimated discharge rate for three models of ANN technique are shown in Figs. 10, 11, and 12. For GRNN model at a spread factor of 1.5 as shown in Table 2, the best value of $R^{2}$ was 0.999 and the lowest values of RMSE and MAE were 0.4817 and 0.32 , respectively. Similarly, RBF model presents its best performance at a spread factor of 4 as demonstrated in Table 3 ; the best value of $R^{2}$ was 0.9985 and the lowest values of RMSE and MAE were 0.2846 and 0.0674 , respectively. While in the case of using MLP model as exhibited in Table 4 , it is found that the highest value of $R^{2}$ was 1 at neurons 
Ibrahim Moukhtar, Adel A. Elbaset, Adel Z. El Dein and Yasunori Mitani/

Journal of Engineering Science and Technology Review 11 (6) (2018) 94 - 106

number of 40 and the lowest RMSE and MAE were 0.003 and 0.0023 , respectively. Furthermore, as presented in Figs. 13,14 , and 15 , it was seen that most of the absolute relative errors for GRNN, RBF, and MLP models are in between $0-$ $0.018,0-0.0325$, and $0-0.00015$, respectively, which are acceptable. Among all, it can be concluded that MLP model with LM-40 is the optimal topology compared to GRNN and RBF models as clarified in Table 4 and Figs. 12 and15.

Table 2 Performance evaluation of GRNN model

\begin{tabular}{|c|c|c|c|}
\hline $\begin{array}{c}\text { Spread } \\
\text { factor }\end{array}$ & RMSE & MAE & $R^{2}$ \\
\hline $\begin{array}{c}0.1 \\
0.5 \\
0.7 \\
1 \\
1.5 \\
1.8 \\
2 \\
\end{array}$ & $\begin{array}{l}1.8346 \\
1.8332 \\
1.7567 \\
1.2242 \\
0.4817 \\
0.6577 \\
0.8127 \\
\end{array}$ & $\begin{array}{c}0.8874 \\
0.8868 \\
0.8502 \\
0.6044 \\
0.32 \\
0.3521 \\
0.402 \\
\end{array}$ & $\begin{array}{l}0.9850 \\
0.9850 \\
0.9862 \\
0.9931 \\
0.9990 \\
0.9990 \\
0.9989 \\
\end{array}$ \\
\hline $\begin{array}{c}\text { Table } 3 \mathrm{Pe} \\
\begin{array}{c}\text { Spread } \\
\text { factor }\end{array}\end{array}$ & $\frac{\text { nce eval }}{\text { RMSE }}$ & $\frac{f \mathrm{RBF}}{\mathbf{M A E}}$ & $\overline{R^{2}}$ \\
\hline 1.2 & 62.4509 & 24.3655 & 0.1848 \\
\hline 1.7 & 7.8996 & 3.0197 & 0.9894 \\
\hline 2 & 2.6198 & 0.7555 & 0.9996 \\
\hline 2.3 & 2.3529 & 0.4298 & 0.9999 \\
\hline 2.5 & 2.2988 & 0.3994 & 0.9999 \\
\hline 3 & 1.2406 & 0.23184 & 1 \\
\hline 3.5 & 0.4539 & 0.0944 & 0.9829 \\
\hline 4 & 0.2846 & 0.0674 & 0.9985 \\
\hline 4.3 & 0.353 & 0.0616 & 1 \\
\hline
\end{tabular}

Table 4. Performance evaluation of MLP model

\begin{tabular}{cccc}
\hline $\begin{array}{c}\text { Neurons } \\
\text { number }\end{array}$ & RMSE & MAE & $\boldsymbol{R}^{\mathbf{2}}$ \\
\hline LM-40 & 0.003 & 0.0023 & 1 \\
LM-35 & 0.0062 & 0.0056 & 1 \\
LM-30 & 0.0059 & 0.0049 & 1 \\
LM-25 & 0.0162 & 0.0125 & 1 \\
LM-20 & 0.0105 & 0.0082 & 1 \\
LM-15 & 0.0221 & 0.0171 & 0.9999 \\
LM-10 & 0.0174 & 0.0145 & 1 \\
LM-5 & 0.0313 & 0.0231 & 0.9998 \\
LM-3 & 0.991 & 0.7578 & 0.9592 \\
\hline
\end{tabular}

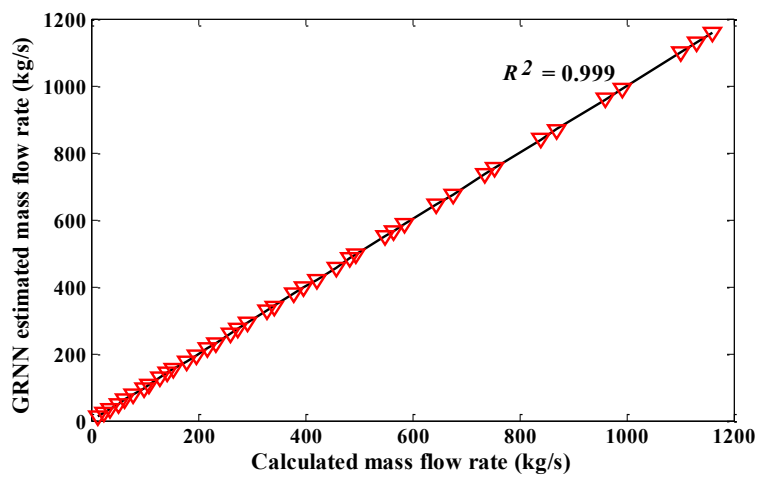

Fig. 10. Comparison between the calculated mass flow rate and the estimated by GRNN model

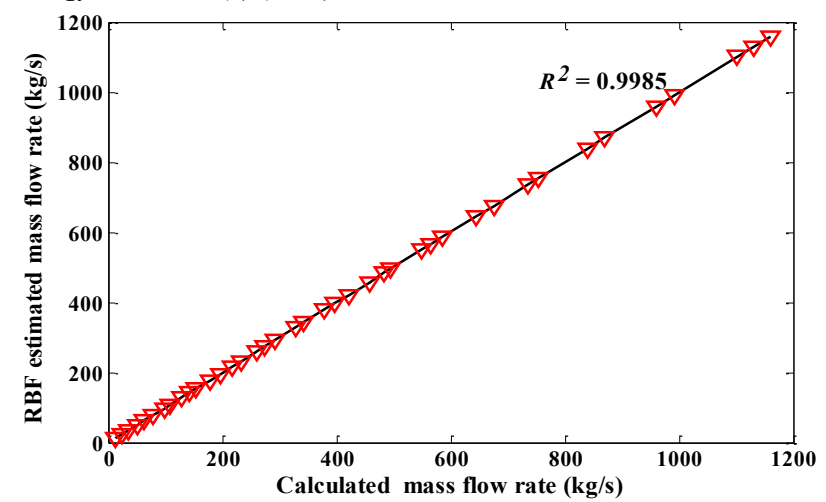

Fig. 11. Comparison between the calculated mass flow rate and the estimated by RBF model

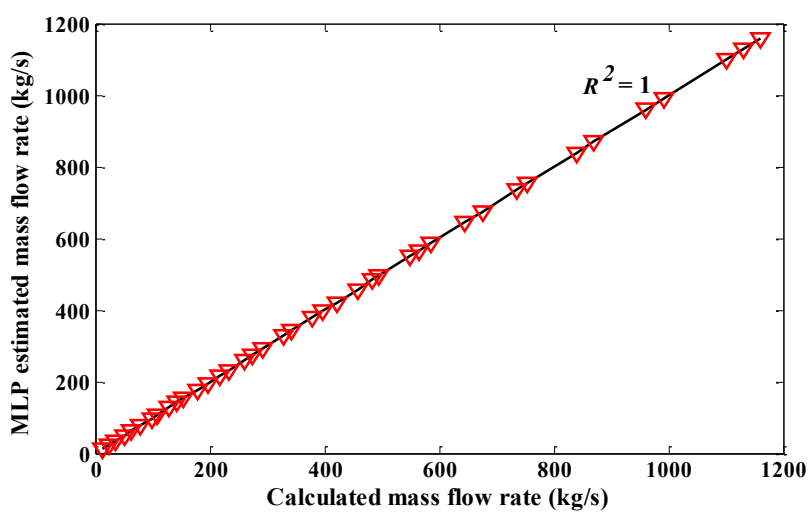

Fig. 12. Comparison between the calculated mass flow rate and the estimated by MLP model

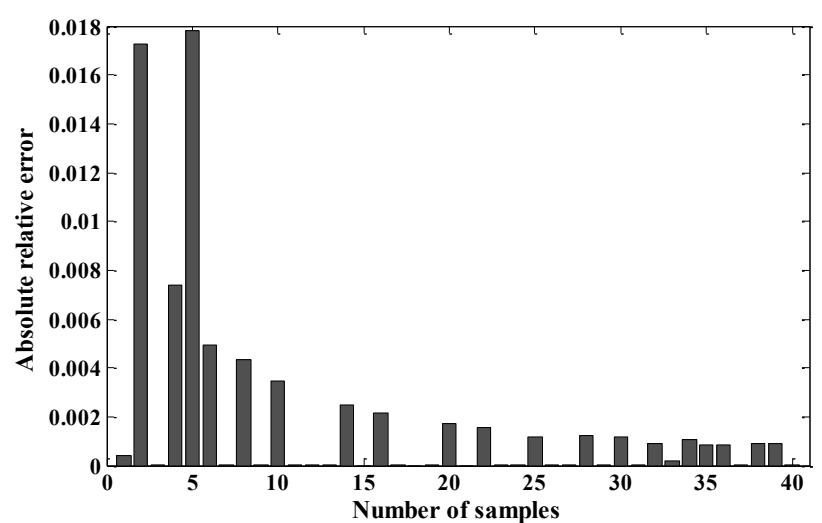

Fig. 13. Relative error of GRNN model at all data samples

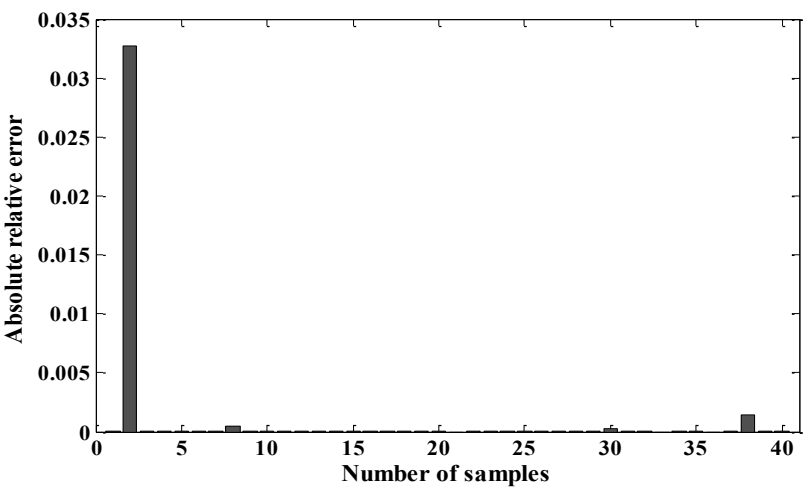

Fig. 14. Relative error of RBF model at all data samples 


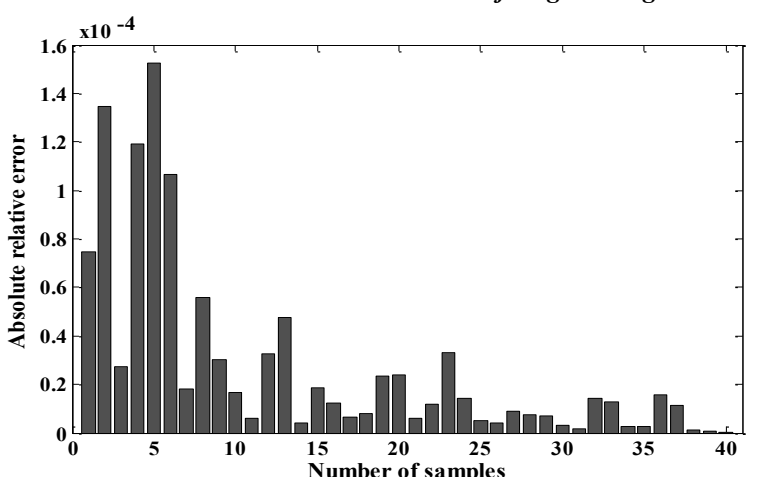

Fig. 15. Relative error of MLP model at all data samples

Figure 16 shows the comparison between the calculated and simulated hourly solar radiation by using DI method and SAM software, respectively. It is found that a slight difference between the two methods particularly during summer season. DI method result is slightly larger than SAM result. This slight difference between the two methods is due to the meteorological data and solar resource in SAM weather file. Indeed, this file contains typical data for one year that may be obtained from satellite, ground measurements, or combination of the two. Similarly, thermal power of the adopted model and SAM are compared in Fig. 17. In this simulation, the receiver efficiency of the adopted model was set at $90 \%$. As well, thermal power of the adopted model is slightly larger than SAM result during summer season due to the calculated higher solar radiation by DI method as explained above in Fig. 16.

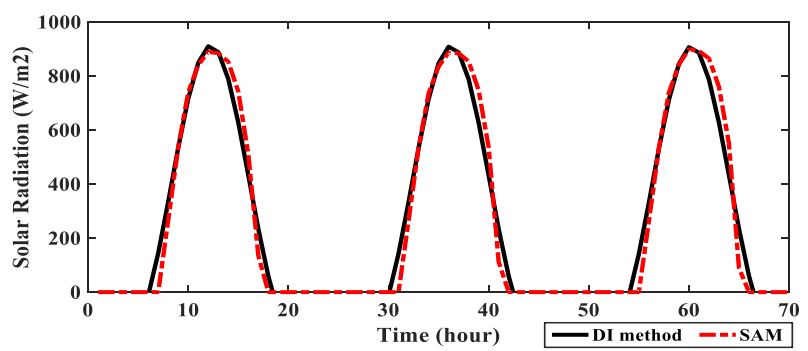

(a)

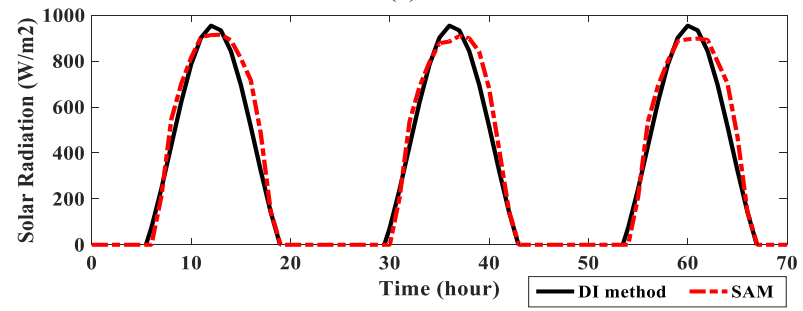

(b)

Fig. 16. Hourly solar radiation: (a) winter days (1-3 January) and (b) summer days (21-23 June)

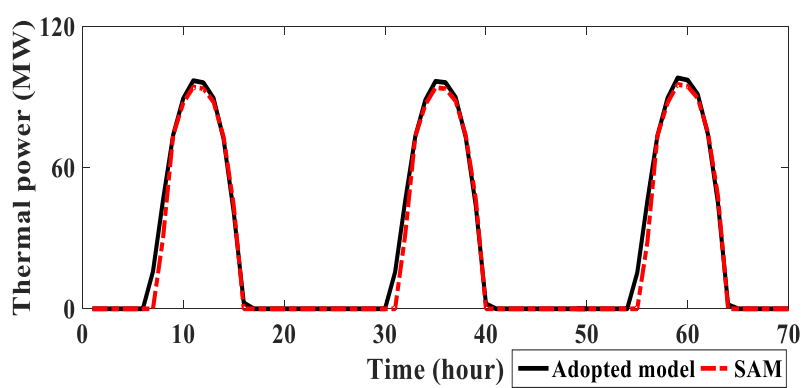

(a)

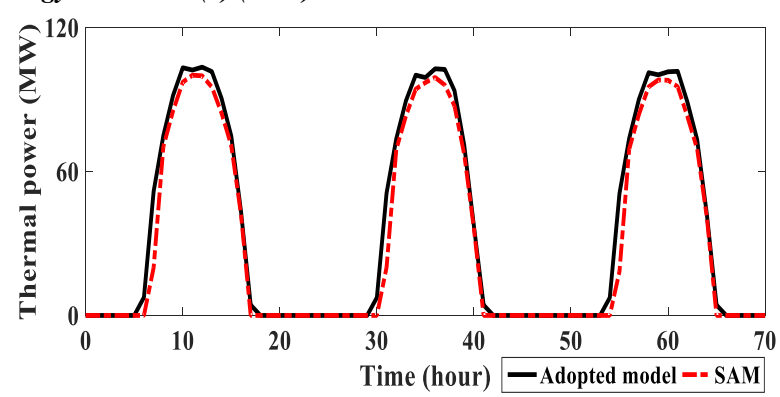

(b)

Fig. 17. Receiver incident thermal power: (a) winter days (1-3 January) and (b) summer days (21-23 June)

Mass flow rate, receiver outlet temperature, and electrical output power for the adopted model and SAM during winter and summer season are presented in Figs. 18(a), (b), and (c) and 19(a), (b), and (c), respectively. An inconsiderable deviation between the results of the adopted model and SAM depends on an existence of a slight difference between the adopted and simulated thermal power, and different control strategy and operating conditions. Discharge rate from CST to tower receiver proportional to the available radiation during different seasons of the year as shown in Figs. 18(a) and 19(a). It is clear that the simulated mass flow rate by MLP neural network and SAM are identical. However, there is a small difference at the beginning of discharge owing to the difference in the minimum value of the thermal power of the two methods as explained in section (6) It is also observed in Figs. 18(b) and 19(b) that the receiver outlet temperature is constant during the operation time because discharge from CST varies with thermal power at the receiver.

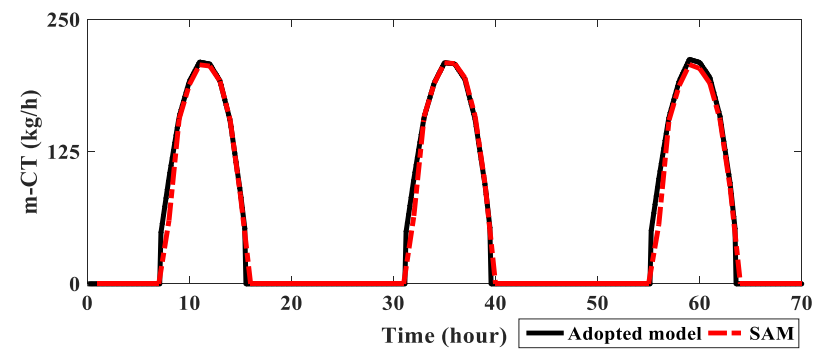

(a)

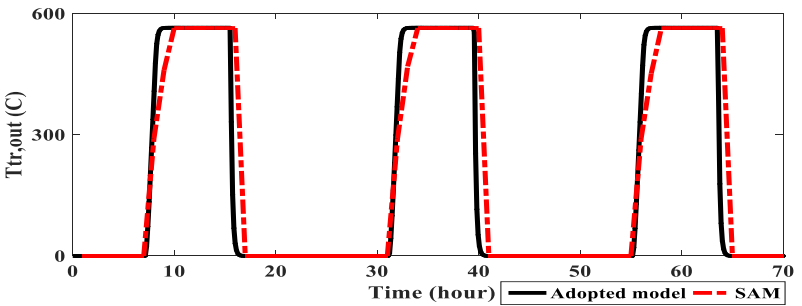

(b)

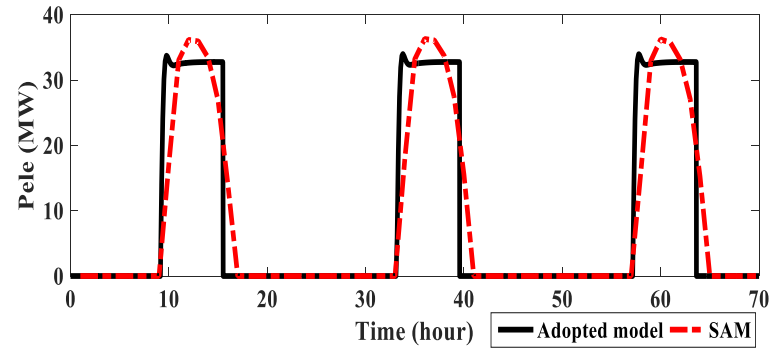

(c)

Fig. 18. Comparison between adopted model and SAM during winter days: (a) Discharge rate, (b) Receiver outlet temperature, and (c) CTR output power 
Ibrahim Moukhtar, Adel A. Elbaset, Adel Z. El Dein and Yasunori Mitani/

Journal of Engineering Science and Technology Review 11 (6) (2018) 94 - 106

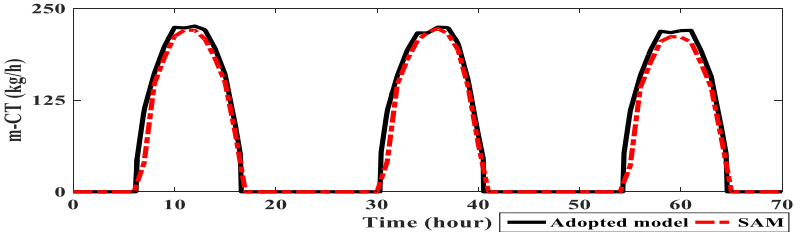

(a)

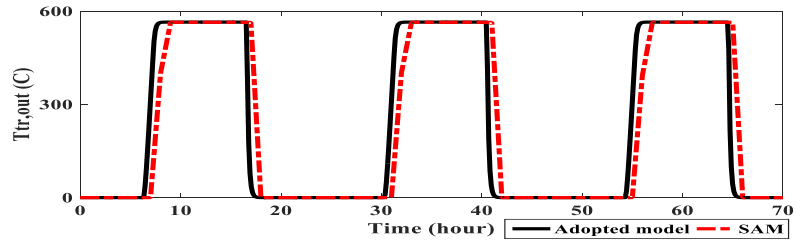

(b)

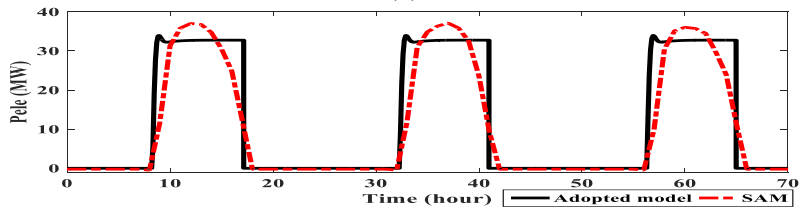

(c)

Fig. 19. Comparison between adopted model and SAM during summer days: (a) Discharge rate, (b) Receiver outlet temperature, and (c) CTR output power
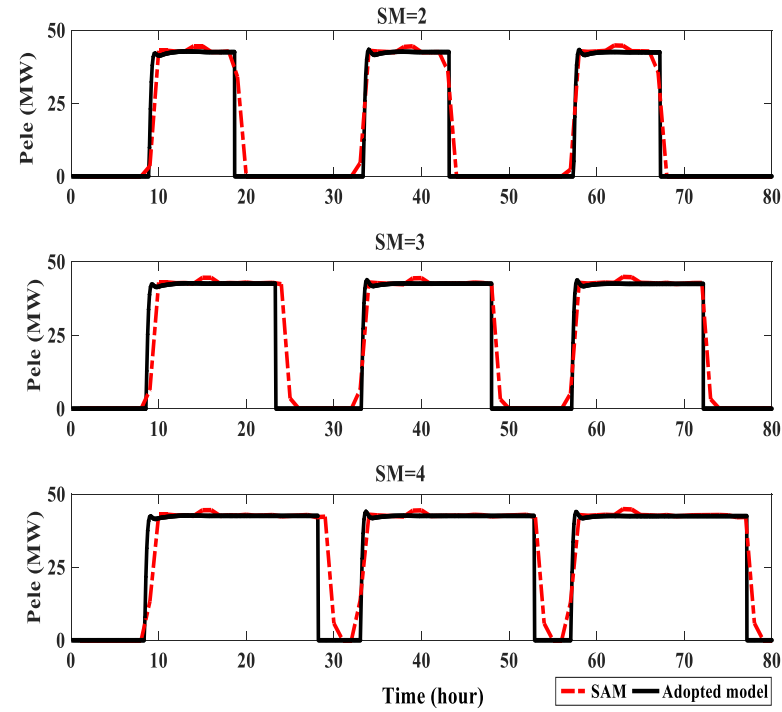

Fig. 20. Comparison of adopted model and SAM power: (a) $\mathrm{SM}=2$, (b) $\mathrm{SM}=3$, (c) $\mathrm{SM}=4$

Generator output of the adopted model is compared to SAM output power during winter and summer days as described in Figs. 18(c) and 19(c), respectively. SAM output power is not regular because its strategy depends on the conditions of both SF and TES. While in the present work, the power has been regulated by making the output directly relies on HST conditions as explained in section (6). However, if the area of the generated power curve is calculated, the energy is almost equal to the two methods. In addition, the output power for the two methods has been compared at different SM as described in Fig. 20. The adopted model output is reasonably close to the simulated power by SAM.

\section{Conclusion}

This paper addresses the modelling issue of a central tower receiver with thermal energy storage from a reasonably simplified model perspective. Where the simplified model of CTR plant is appropriate for the reliability study of the power system by using MC method. For model simplification, this study uses an ANN technique to control the receiver outlet temperature by adjusting the amount of HTF that passes through a tower receiver. The calculated mass flow rates were successfully investigated using three types of ANN models such as GRNN, RBF, and MLP. The performance of the ANN models was tested by different statistical parameters such as RMSE, MAE, and $R^{2}$. Statistical results exhibited that MLP model with LM-40 was very satisfactory compared to GRNN and RBF models. Furthermore, in the testing process, MLP model based on LM-40 displayed the lowest values of RMSE (0.003) and MAE (0.0023) and the highest value of $R^{2}$ (1). These results demonstrate that ANN accuracy is satisfactory and it can be used to estimate HTF discharge rate. Therefore, the receiver outlet temperature remains constant at the design value over the operation time in spite of the changes in direct solar radiation and receiver inlet temperature. The simulation results were compared with those simulated by SAM software to verify the proposed model effectiveness. These comparisons showed that the adopted model results are in good agreement with SAM results. In addition, the proposed CTR-ANN model reduces the required input data and provides the desired simplicity for CTR modelling. It can be concluded that the adopted model holds potential as a general tool for modelling, predicting, and analysing the performance of the CTR power plant in a simple and fixable manner. For more accurate model, CTR plant losses will be taken into consideration in the future work.

This is an Open Access article distributed under the terms of the Creative Commons Attribution License

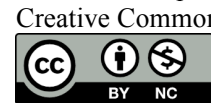

\section{References}

[1] Owusu, P.A., Sarkodie, S. A., "A review of renewable energy sources, sustainability issues and climate change mitigation", Cogent Engineering Journal, 3 (1), pp. 1-14, (2016).

[2] Ibrahim M., A.A. Elbaset, A.Z. El Dein, Yaser Q, and Yasunori M., "Concentrated Solar Power Plants Impact on PV Penetration Level and Grid Flexibility under Egyptian Climate", AIP Conference Proceedings, 1968(1), pp. 1-7, (2018).

[3] IEA-ETSAP, and IRENA (2013), "Concentrating Solar Power Technology Brief", available at https://refman.energytransitionmodel.com/publications/1922.

[4] EASAC Policy Report Nr 16 (2011), "Concentrating solar power: its potential contribution to a sustainable energy future", available at

http://www.easac.eu/fileadmin/Reports/Easac_CSP_WebFinal.pdf.
[5] International Energy Agency (2010), "Concentrating Solar Power Roadmap", available at

http://www.iea.org/publications/freepublications/publication/tech nology-roadmap-concentrating-solar-power.html.

[6] Paul, D., and Mark, M., "Enabling Greater Penetration of Solar Power via the Use of CSP with Thermal Energy Storage", Technical Report, National Renewable Energy Laboratory, pp. 124, (2011).

[7] Faraz, T., "Benefits of Concentrating Solar Power over Solar Photovoltaic for Power Generation in Bangladesh", $2^{\text {nd }}$ International Conference of Developments in Renewable Energy Technology (ICDRET), Dhaka, Bangladesh, pp. 1-5, (2012).

[8] Llorente, I., Luis, J.A., and Blanco, D, "Performance model for parabolic trough solar thermal power plants with thermal storage: Comparison to operating plant data", Elsevier Journal, Solar Energy, 85(10), pp. 2443-2460, (2011). 
9] Vergura, S., and Fronzo, V., "Matlab based Model of 40-MW Concentrating Solar Power Plant", International Conference on Renewable Energies and Power Quality, Santiago de Compostela, Spain, pp. 1259-1263, (2012).

[10] International Renewable Energy Agency, "Renewable Energy Technologies: Cost Analysis Series: Concentrating Solar Power", Power Sector, 1(2/5), pp. 1-41, (2012).

[11]Billinton, R., Li, W., "Reliability assessment of electrical power systems using Monte Carlo methods", (1st ed.), Springer Science+Business Media, LLC, (1994).

[12] Clifford, K.H., "Software and Codes for Analysis of Concentrating Solar Power Technologies", SANDIA Report, pp. 1-35, (2008).

[13]Bode, S., and Gauché, P., "Review of Optical Software for Use in Concentrating Solar Power Systems", $1^{\text {st }}$ SASEC conference, Stellenbosch, South Africa, pp. 1-8, (2012).

[14]El Hefni, B., "Dynamic modeling of concentrated solar power plants with the ThermoSysPro library (Parabolic Trough collectors, Fresnel reflector and Solar-Hybrid", Elsevier, Energy Procedia, 49, pp. 1127-1137, (2014).

[15]Zhang, J.B.; Marcos, J.C.V.; El-Hefni, B.; Wang, Z.F.; Chen, G.F., Ma, G.C., Li, X., and Soler, R., "Dynamic simulation of a $1 \mathrm{MWe}$ concentrated solar power tower plant system with Dymola ${ }^{\circledR}$, Elsevier, Energy Procedia, 49, pp. 592-1602, (2014).

[16]Hummon, M., Denholm, P., Jorgenson, J., and Mehos, M. "Modelling Concentrating Solar Power with Thermal Energy Storage for Integration Studies Preprint", $3^{\text {rd }}$ International conference on Integration of Solar Power in Power Systems, London, England, pp. 21-22, (2013).

[17]Blair, N.J., Gilman, P., and Dobos, A.P., "Comparison of Photovoltaic Models in the System Advisor Model", Solar 2013 Conference, Baltimore, Maryland, pp. 1-6, (2013).

[18]Blair, N., Dobos, A.P., Freeman, J., Neises, T., and Wagner, M., "System Advisor Model, SAM 2014.1.14: General Description", Technical Report, National Renewable Energy Laboratory, pp. 1$13,(2014)$

[19] Gafurov, T., Usaola, J., and Prodanovic, M., "Modelling of concentrating solar power plant for power system reliability studies", IET Renewable Power Generation, 9(2), pp. 120-130, (2015).

[20]Camacho, E.F., Rubio, F. R., Berenguel, B., Valenzuela, L., “A survey on control schemes for distributed solar collector fields Part I: Modeling and basic control approaches", Elsevier, Solar Energy, 81(10), pp. 1240-1251, (2007).

[21] Camacho, E.F., Rubio, F. R., Berenguel, B., Valenzuela, L., “A survey on control schemes for distributed solar collector fields Part II: Advanced control approaches", Elsevier, Solar Energy, 81(10), pp. 1240-1251, (2007).

[22] Kalogirou, S.A. "Artificial neural networks in renewable energy systems applications: a review", Renewable and Sustainable Energy Reviews, 5(4), pp. 373-401, (2001).

[23]Harish, K.G. and Radha K.P., "Application of ANN technique to predict the performance of solar collector systems - A review", Renewable and Sustainable Energy Reviews, 84, pp. 75-88, (2018).

[24] Ibrahim M., A.A. El baset, A.Z. El Dein, Yaser Q, Evgeny B., Dmitry U., and Yasunori M, “A Developed Concentrated Solar Power Model Using Artificial Neural Network Technique", $19^{\text {th }}$ International Middle East Power Systems Conference (MEPCON), Menoufia, Egypt, pp. 1346-1351, (2017).

[25]Pacheco, J.E., Wolf, T, and Muley, N., "Incorporating Supercritical Steam Turbines into Advanced Molten-Salt Power Tower Plants: Feasibility and Performance", SANDIA Report, Sandia National Laboratories, pp. 1-39, (2013).

[26] Goswami, D.Y., "Principles of Solar Engineering" ( $3^{\text {rd }}$ ed. $)$, Boca Raton, London: Taylor \& Francis, (2015).

\section{Appendix A}

Sun position Parameters

Declination angle $\delta_{s}$ :

$\delta_{s}=23.45 s\left(\frac{360(284+N)}{365}\right)$

Solar hour angle $h_{s}$

$h_{s}=15\left(t_{s}-12\right)$

Solar time $t_{s}$ :

$t_{s}=t+E+4\left(L_{s}-L_{l o c}\right)$
[27] Shen, C., He, Y., Liu, Y., and Tao, W., "Modelling and simulation of solar radiation data processing with Simulink", Elsevier, Simulation Modelling Practice and Theory, 16(7), pp. 721-735, (2008).

[28]Kalogirou, S.A., "Solar Energy Engineering: Processes and Systems", ( $2^{\text {nd }}$ ed.), Amsterdam, Boston, Heidelberg, London, (2014).

[29]Duffie, J.A., and Beckman, W.A., "Solar Engineering of Thermal Processes", $\left(4^{\text {th }}\right.$ ed. $)$, Hoboken, New Jersey: John Wiley \& Sons, (2013)

[30]A renewable energy resource web site sponsored by NASA's Applied Science Program. Available at https://eosweb.larc.nasa.gov/sse/

[31] Wei, X., Lu, Z., Wang, Z., Yu, W., Zhang, H., and Yao, Z., “A new method for the design of the heliostat field layout for solar tower power plant", Elsevier, Renewable Energy, 35(9), pp. 1970-1975, (2010).

[32] Macchi, E., and Astolfi, M., "Organic Rankine Cycle (ORC) Power Systems: Technologies and Applications", (1't ed.), Woodhead Publishing, (2016).

[33]Zohuri, B., "Compact Heat Exchangers: Selection, Application, Design and Evaluation", ( $1^{\text {st }}$ ed.), Springer International Publishing Switzerland, (2017).

[34]Kopp, J.E., "Two-Tank Indirect Thermal Storage Designs for Solar Parabolic Trough Power Plants", Master's thesis, University of Nevada Las Vegas, Hughes College of Engineering, (2004).

[35] Padilla, R.V., "Simplified Methodology for Designing Parabolic Trough Solar Power Plants", Doctor's thesis, College of Engineering, University of South Florida, (2001).

[36] Ibrahim M., A.A. El baset, A.Z. El Dein, Yaser Q, Evgeny B., Dmitry U., and Yasunori M, "Modelling of Central Tower Receiver Plant for Partial Load Conditions to Support Microgrid Reliability", International Conference on Electrical, Electronics, Computers, Communication, Mechanical and Computing (EECCMC2018), Tamil Nadu, India, 2018.

[37]Patnode, A.M., "Simulation and performance evaluation of parabolic trough solar power plants", Master's thesis, University of Wisconsin-Madison, College of Engineering, (2006).

[38]Haykin, S., "Neural networks", ( $1^{\text {st }}$ ed.), MacMillan College Publishing Company, (1994).

[39]Klerfors, D., "Artificial neural networks", ( $1^{\text {st }}$ ed.), Project MISB420-0, Saint Louis University, (1998).

[40]Kung, S.Y., "Digital neural networks", ( $1^{\text {st }}$ ed.), Prentice-Hall, (1993).

[41]Howard D., and Mark B., "Neural Networks Toolbox", ( $7^{\text {th }}$ ed.), MathWorks, Inc, (2001).

[42]L. Fausett, "Fundamentals of Neural networks", ( $1^{\text {st }}$ ed.), Prentice Hall, (1994).

[43] Ibrahim M., A.A. El baset, A.Z. El Dein, Yaser Q, Evgeny B., Dmitry U., and Yasunori $M$, "Electric power regulation and modeling of a central tower receiver power plant based on artificial neural network technique", Journal of Renewable and Sustainable Energy, 10(4), pp. 1-20, (2018).

[44]Harish, K.G. and Radha K.P., "Investigation of thermal performance of unidirectional flow porous bed solar air heater using MLP, GRNN, and RBF models of ANN technique", Thermal Science and Engineering Progress, 6, pp. 226-235, (2018).

[45] Wagner, M., Gilman, P., "Technical manual for the SAM physical trough model" Technical Report, NREL, pp. 1-114, (2011).

[46] Wagner, M., "Simulation and predictive performance modeling of utility-scale central receiver system power plants", Master's thesis, University of Wisconsin-Madison, (2008).

where $t$ is the local time

Equation time $E$ :

$E=$ 
$229.2(0.000075+0.001868 \cos B-0.032077 \sin B-$

$0.014615 \cos 2 B-0.04089 \sin 2 B)$

$B$ is defined as:

$B=\frac{360}{365}(N-1)$

Solar zenith angle $\theta_{z}$ :

$\theta_{z}=90-\alpha_{s}$

\section{DI method Parameters}

$r_{d}=\frac{\pi}{24}\left(\frac{\cosh _{s}-\cosh _{S S}}{\sinh _{s S}-\frac{\pi}{180} h_{S S} \cosh h_{S S}}\right)$

$r_{t}=r_{d}\left(\frac{1+q\left(\frac{a_{2}}{a_{1}}\right) A\left(h_{S S}\right) r_{d}\left(\frac{24}{\pi}\right)}{q\left(\frac{a_{2}}{a_{1}}\right) B\left(h_{S S}\right)}\right)$

The hour angles of sunset $h_{s s}$ :

$h_{s s}=\cos ^{-1}\left(\tan L \cdot \tan \delta_{s}\right)$

$A\left(h_{s s}\right)=\sinh _{s s}-h_{s S} \cosh h_{s s}$

$B\left(h_{s s}\right)=h_{s s}\left(0.5+\cos ^{2} h_{s s}\right)-0.75 \sin \left(2 h_{s s}\right)$

$q=\cos L-\cos \delta_{s}$

\section{Nomenclatures}

$A_{h s} \quad$ Heliostat area, $\mathrm{m}^{2}$

$C_{H T F} \quad$ Specific heat of the heat transfer fluid

E Equation of time, min

$h_{s} \quad$ Solar hour angle

$\bar{H}_{d} \quad$ Long-term average daily diffuse irradiation on horizontal surface, $\mathrm{kWh} / \mathrm{m}^{2} /$ day

$\bar{H}_{h} \quad$ Long-term average daily total irradiation on horizontal surface $\mathrm{kWh} / \mathrm{m}^{2} /$ day

I Total solar radiation

$L \quad$ Latitude of the location

$L_{l o c} \quad$ Longitude of the location

$L_{s t} \quad$ Standard meridian for the local time zone

$\dot{m}_{H T} \quad$ Hot tank outlet mass flow rate

$\dot{m}_{H T, \text { ref }} \quad$ HTF mass flow rate at the reference full-load condition

$\dot{m}_{C T} \quad$ Cold tank outlet mass flow rate

$M_{C T} \quad$ HTF mass within cold storage tank, ton

$M_{H T} \quad$ HTF mass within hot storage tank, ton

$N T U_{\text {ref }} \quad$ Heat transfer unit at the reference full-load condition

$N \quad$ Day of the year

$N_{h s} \quad$ Number of heliostats

$P_{\text {gross }} \quad$ Gross electrical power MW

$P_{t h, t r} \quad$ Solar thermal power

$Q \quad$ Actual heat transfer rate

$Q_{\max } \quad$ Maximum heat transfer rate, MW

$R^{2} \quad$ Coefficient of determination

$r_{d} \quad$ Hourly diffuse ratio to long-term average daily

diffuse irradiation on a horizontal surface

$r_{t} \quad$ Ratio of hourly total to the long-term average daily total irradiation on a horizontal surface

$t \quad$ Local time, hour

$t_{s} \quad$ Solar time, hour

$T_{H T F, \text { hot }}$ $\left(a_{2} / a_{1}\right)$ is the atmospheric extinction effect is given as follow:

$a_{1}=0.4134 K_{t}+0.61197 K_{t}^{2}-0.01886 K_{t} S_{o}+0.00759 S_{o}$ (A13)

$a_{2}=\operatorname{Max}\left(0.054,0.28116+2.2475 K_{t}-1.7611 K_{t}^{2}-\right.$

$\left.1.84535 \sinh _{o}+1.681 \sin ^{3} h_{o}\right)$

The day length (in hours) is obtained as:

$S_{o}=\frac{24}{\pi} h_{S S}$

The daily average clearness index is given by:

$K_{t}=\frac{\bar{H}_{h}}{H_{o}}$

$H_{o}$ is the daily-average extraterrestrial irradiation on a horizontal surface.

$H_{o}=\frac{24}{\pi} h_{s S} R E_{s c} \sinh h_{o}$

where $E_{s c}$ is the solar constant; Esc $=1367 \mathrm{~W} / \mathrm{m}^{2}$

$R=1.00011+0.034221 \cos (B)+0.00128 \sin (B)+$

$0.000719 \cos (2 B)+0.0000 \sin (2 B)$

The daily average solar elevation outside of the atmosphere is $h_{o}$, defined by

$h_{o}=\sin ^{-1}\left(\frac{q A\left(h_{S S}\right)}{h_{S S}}\right)$

$T_{H T F, \text { cold }} \quad$ Receiver inlet temperature, ${ }^{\circ} \mathrm{C}$

$T_{H T F, \text { in }} \quad$ HTF inlet temperature of the heat exchanger

$T_{\text {steam,in }} \quad$ steam inlet temperature of the heat exchanger,

\section{Greek Symbols}

$\rho \quad$ Ground reflectance factor

$\varepsilon \quad$ Effectiveness of heat exchanger

$\eta_{\text {ref }} \quad$ Heliostat reflectivity factor

$\eta_{\text {th }} \quad$ Thermal efficiency

$\eta_{\text {gen }} \quad$ Generator efficiency

$\eta_{\text {rec }} \quad$ Receiver thermal efficiency

$\eta_{\text {fild }} \quad$ Heliostat field efficiency

$\eta_{\cos } \quad$ Cosine factor losses

$\eta_{\text {att }} \quad$ Atmospheric attenuation

$\eta_{s b} \quad$ Shadowing and blocking factor losses

$\alpha_{s} \quad$ Solar altitude angle

$\gamma_{s} \quad$ Azimuth angle

$\gamma \quad$ Surface azimuth angle

$\delta \quad$ Declination angle

$\theta z \quad$ Solar zenith angle

$\theta \quad$ Incidence beam angle

$\beta \quad$ Surface slope

Abbreviations

ANN Artificial neural network

CSP Concentrated solar power

CTR Central tower receiver

CST Cold storage tank

$\mathrm{CO}_{2} \quad$ Carbon dioxide

DNI Direct normal beam

GRNN Generalized regression neural network

HST Hot storage tank

HTF Heat transfer fluid

IEA International Energy Agency

LFR Linear Fresnel reflector

MLP Multi-layer perceptron 
Ibrahim Moukhtar, Adel A. Elbaset, Adel Z. El Dein and Yasunori Mitani/

Journal of Engineering Science and Technology Review 11 (6) (2018) 94 - 106

MSE Mean square error

$\mathrm{MC}$

MAE

NREL

PB

PV

PT

PD

Photovoltaic

Parabolic trough

Parabolic dish
Monte Carlo method

Mean absolute error

National Renewable Energy Laboratory

Power Block
RMSE

RBF

RES

SES

SAM

SF

TES
Root mean square error

Radial basis function

Renewable energy sources

Solar energy systems

System Advisor Model

Solar field

Thermal energy storage 